\title{
Effectiveness of radiotherapy after breast-conserving surgery in older patients with T1-2NO breast cancer
}

\author{
Anna Z. de Boer ${ }^{1,2}(-) \cdot$ Esther Bastiaannet $^{1,2} \cdot$ Nienke A. de Glas $^{2} \cdot$ Perla J. Marang-van de Mheen ${ }^{3} \cdot$ Olaf M. Dekkers ${ }^{4}$. \\ Sabine Siesling ${ }^{5,6} \cdot$ Linda de Munck $^{5} \cdot$ Kelly M. de Ligt ${ }^{5,6} \cdot$ Johanneke E. A. Portielje $^{2} \cdot$ Gerrit Jan Liefers $^{1}$
}

Received: 1 August 2019 / Accepted: 19 August 2019 / Published online: 26 August 2019

(c) The Author(s) 2019

\begin{abstract}
Purpose In the Netherlands, radiotherapy after breast-conserving surgery (BCS) is omitted in up to 30\% of patients aged $\geq 75$ years. Although omission of radiotherapy is considered an option for older women treated with endocrine treatment, the majority of these patients do not receive systemic treatment following Dutch treatment guidelines. Therefore, the aim of this study was to evaluate the effect of omission of radiotherapy on locoregional recurrence risk in this patient population. Methods Patients aged $\geq 75$ years undergone BCS for T1-2N0 breast cancer diagnosed between 2003 and 2009 were selected from the Netherlands Cancer Registry. To minimize confounding by indication, hospital variation was used to assess the impact of radiotherapy-use on locoregional recurrence risk using cox proportional hazards regression. Hazards ratios with 95\% confidence interval (CI) were estimated.

Results Overall, 2390 patients were included. Of the patients with hormone receptor-positive breast cancer, 39.3\% received endocrine treatment. Five-year incidences of locoregional recurrence were 1.9\%, 2.8\%, and 3.0\% in patients treated at hospitals with higher (average radiotherapy-use $96.0 \%$ ), moderate (88.0\%), and lower radiotherapy-use $(72.2 \%)$ respectively, and nine-year incidences were $2.2 \%, 3.1 \%$, and 3.2\% respectively. Adjusted hazard ratios were 1.46 (95\% CI 0.77-2.78) and 1.50 (95\% CI 0.79-2.85) for patients treated at hospitals with moderate and lower radiotherapy-use, compared to patient treated at hospitals with higher radiotherapy-use.

Conclusions Despite endocrine treatment in only 39.3\%, locoregional recurrence risk was low, even in patients treated at hospitals with lower radiotherapy-use. This provides reasonable grounds to consider omission of radiotherapy in patients aged $\geq 75$ years with $\mathrm{T} 1-2 \mathrm{~N} 0$ breast cancer.
\end{abstract}

Keywords Breast cancer $\cdot$ Older patients $\cdot$ Breast-conserving treatment $\cdot$ Locoregional recurrence

Electronic supplementary material The online version of this article (https://doi.org/10.1007/s10549-019-05412-8) contains supplementary material, which is available to authorized users.

Anna Z. de Boer

a.z.de_boer@lumc.nl

1 Department of Surgery, Leiden University Medical Center, Location J10-71, Postzone K6-R, P.O. Box 9600, 2300 RC Leiden, The Netherlands

2 Department of Medical Oncology, Leiden University Medical Center, Leiden, The Netherlands

3 Department of Medical Decision-Making, Leiden University Medical Center, Leiden, The Netherlands

\section{Introduction}

Breast-conserving surgery (BCS) followed by radiotherapy is the standard treatment for early stage breast cancer. However, various randomized clinical trials (RCTs) have investigated omission of the radiotherapy in older patients

4 Department of Clinical Epidemiology, Leiden University Medical Center, Leiden, The Netherlands

5 Department of Research and Development, Netherlands Comprehensive Cancer Organisation, Utrecht, The Netherlands

6 Department of Health Technology and Services Research, Technical Medical Center, University of Twente, Enschede, The Netherlands 
as the additional benefit is expected to decrease with declining residual life expectancy and increasing risk of dying from other causes with age [1-3]. These RCTs demonstrated a small benefit in locoregional control from radiotherapy, but no effect on distant metastasis-free or disease-specific survival.

As no survival benefit was demonstrated and locoregional recurrences can be treated with surgery, in 2004, omission of radiotherapy was incorporated in the National Comprehensive Cancer Network (NCCN) guideline as treatment option for patients aged $\geq 70$ years with stage 1 breast cancer provided that they are treated with endocrine therapy [4]. However, this recommendation had only limited effect on radiotherapy-use in clinical practice [5]. Furthermore, other guidelines such as recommendations from the Society of Geriatric Oncology (SIOG) and European Society of Breast Cancer Specialists (EUSOMA) still state that radiotherapy should be considered in all elderly patients because it decreases the risk of locoregional recurrence [6].

The reluctance regarding omission of radiotherapy could be partially explained by concerns of clinicians about lower endocrine therapy-use and adherence in the true older population of patients with breast cancer compared to trial populations [7, 8]. The RCTs exclusively included patients using endocrine therapy $[1,2]$. Moreover, adherence to endocrine treatment was supposedly higher than in the general older population. Although the aim of endocrine therapy is to reduce the risk of distant metastasis and improve breast cancer specific survival, the systemic therapy may also have a locoregional effect.

In the Netherlands, radiotherapy after BCS is omitted in up to $30 \%$ of patients aged $\geq 75$ years, and the majority of these patients do not receive systemic treatment following Dutch treatment guidelines [9]. On the one hand, the omission of radiotherapy in the absence of endocrine treatment may potentially result in higher locoregional recurrence risks. On the other hand, older patients participating in trials are often a relatively young and healthy selection of the general older population [10]. Due to higher competing mortality risks in the general older population, the radiotherapy benefit may actually be smaller than demonstrated in the selected trial populations.

Population-based data can give important insight in the effectiveness of radiotherapy after BCS for the general older population, provided that confounding by indication is appropriately handled. Because confounding by unmeasured factors was expected, a method which can avoid such confounding was considered most effective in obtaining a valid effect estimate. Therefore, the aim of this study was to assess the effect of omission of radiotherapy after BCS on locoregional recurrence risk in patients aged $\geq 75$ years with T1-2N0 breast cancer using hospital variation in radiotherapy-use as an instrumental variable-like approach.

\section{Methods}

All patients aged $\geq 75$ years who underwent BCS for T1-2N0 breast cancer between 2003 and 2009 were selected from the Netherlands Cancer Registry (NCR) and included in this study. The NCR is a database on cancer diagnosis and treatment. It is hosted by the Netherlands Comprehensive Cancer Organisation (IKNL) and receives reports of diagnosed malignancies from the nationwide network and registry of histopathology and cytopathology in the Netherlands (PALGA), which are confirmed and completed by the national hospital discharge databank. Trained data managers of the IKNL regularly collect data on diagnosis, staging, and treatment from medical records using international coding rules. In addition, information on recurrence status and comorbidity is collected for specific research purposes.

Breast cancer stage is defined according to the TNM Classification of Malignant Tumors for breast cancer (6th edition) [11]. Clinical $\mathrm{T}$ or $\mathrm{N}$ stage is used if pathological $\mathrm{T}$ or $\mathrm{N}$ stage is unknown. Recurrences are defined according to consensus-based definitions for classification of breast cancer recurrence [12]. Ipsilateral breast, chest wall, axillary, and supraclavicular lymph nodes recurrence are considered a locoregional recurrence. For the current study, recurrence status was available for a minimum of five years after diagnosis for all patients. We used a Landmark approach to avoid bias due to immortal time between diagnosis, surgery and radiotherapy. Therefore, follow-up started 3 months after diagnosis. Endpoint for follow-up was time of recurrence, death, or last followup visit, whichever came first. Vital status was available until January 31st 2017 through linkage of NCR data with the Municipal Personal Records database. Information on comorbidity at time of diagnosis was retrospectively collected for patients diagnosed during incidence years 2007-2009.

\section{Hospital radiotherapy variation}

We used an instrumental variable-like approach to minimize confounding by indication by using hospital variation in radiotherapy-use [13]. Treatment decisions in older patients with breast cancer are influenced by aspects of general health such as physical and cognitive functioning, which also affect outcome. As information regarding these factors is not available in cancer registries, conventional statistical methods are unable to take these factors into account. Consequently, results are at high risk of bias due to residual confounding [13]. To minimize this problem, we used variation in radiotherapy-use among hospitals in 
which patients underwent surgery to assess the effect of radiotherapy. We assumed that hospitals are independent of breast cancer related prognostic factors, given that all hospitals in the Netherlands provide breast cancer care and older patients generally go to the nearest hospital. Three groups were constructed using tertiles of radiotherapy-use, based on the percentage of patients treated with radiotherapy within each hospital: higher level (range 92.3-100\%), moderate (range 83.3-92.3\%), and lower (range 0-83.3\%) radiotherapy-use hospitals. Characteristics of patients treated at higher, moderate, and lower radiotherapy-use hospitals were presented. The characteristics of patients who were treated with and without radiotherapy were also presented to demonstrate the effect on confounding of using hospital variation instead of comparing treated and untreated patients directly.

\section{Statistical analysis}

Statistical analysis was performed with SPSS 23.0 and STATA 12.1. Multiple imputation by chained equation was performed to account for missing values, assuming that data were missing at random [14]. Imputation models were applied including incomplete and complete variables. Analyses were based on the pooled results of 25 imputed sets according to Rubin's rules [15]. Pearson's $\chi^{2}$ tests were used to assess differences in characteristics between patients who were treated with and without radiotherapy, and between patients treated at hospitals with different levels of radiotherapy-use. Cumulative incidences of locoregional recurrence were calculated using the Cumulative Incidence Competing Risk method, considering distant recurrence and death without recurrence as competing events [16]. Cox proportional hazards models were used to estimate hazard ratios (HRs) with $95 \%$ confidence intervals (CIs) to compare locoregional recurrence risk in patients treated at hospitals with different levels of radiotherapy-use. The higher radiotherapy-use group was used as reference group. We adjusted by multivariable analysis for imbalances that were statistically significant. The scaled Schoenfeld residuals of the covariates over time were tested for a non-zero slope in a generalized linear regression. No violations were found. As recurrence status for patients diagnosed between 2003 and 2006 was not available after 5 years, a sensitivity analysis was performed with follow-up truncated at 5 years. To avoid immortal time bias, a Landmark approach was used, starting follow-up at 3 months after diagnosis. All statistical tests were two-sided.

\section{Results}

Overall, 2390 patients with T1-2N0 breast cancer aged $\geq 75$ years were included. Median age was 79.2 years [interquartile range (IQR) 76.4-82.5 years]. Table 1 shows clear differences in characteristics between patients treated with and without radiotherapy. Patients treated with radiotherapy were younger and had less comorbidity compared to patients treated without radiotherapy. With regard to tumor characteristics, patient treated with radiotherapy had smaller tumors, more often hormone receptor-positive tumors, and surgery was irradical in fewer patients. Furthermore, only $32.6 \%$ of the patients treated with radiotherapy received endocrine therapy, compared to $54.7 \%$ in patient treated without radiotherapy $(p=0.023)$. Notably, of the patients with hormone receptor-positive tumors in this study, $39.3 \%$ received endocrine treatment.

The patients were divided into tertiles based on radiotherapy-use within each hospital (Table 2). The average radiotherapy-use was $96.0 \%$ in the higher-use, $88 \%$ in the moderate-use, and $72.2 \%$ in the lower-use hospitals. The groups included patients from 46, 35, and 47 different hospitals respectively. Comorbidity, an important determinant of receiving radiotherapy, and tumor characteristics were equally distributed over the groups. An imbalance in age distribution remained, patients treated in lower-use hospitals were older ( $17.8 \%$ of the patients was aged $>85$ years) compared to patients treated in higher-use and moderateuse hospitals $(8.4 \%$ and $11.2 \%, p<0.001)$. Furthermore, endocrine treatment was more often prescribed in patients treated in lower-use hospitals (40.0\%) compared to patients treated in higher-use and moderate-use hospitals (34.3\% and $32.5 \%$ respectively, $p=0.023$ ). Another imbalance was observed for type of hospital as academic hospitals were overrepresented in the lower-use group (14.2\% compared to $4.6 \%$ in the higher-use and $3.7 \%$ in the moderate-use group, $p<0.001$ ).

Out of the 2390 patients, 186 patients were lost to follow-up and 10 patients died during the first 3 months after diagnosis. For the 2194 patients included in the time-toevent analysis (Landmark approach), median follow-up was 4.8 years starting from 3 months after diagnosis (IQR 4.8-4.8, range $0.03-10.8$ years), during which 61 patients had a locoregional recurrence. Cumulative incidences of locoregional recurrence by hospital level radiotherapy-use are graphically represented in Fig. 1. Five-year cumulative incidences were $1.9 \%, 2.8 \%$, and $3.0 \%$ in the higher-use, moderate-use and lower-use group, and nine-year cumulative incidences were $2.2 \%, 3.1 \%$, and $3.2 \%$ respectively (Table 3).

Results of the Cox proportional hazards analysis are shown in Table 3. In univariable analysis, the HRs were 
Table 1 Characteristics of patients treated with and without radiotherapy

\begin{tabular}{|c|c|c|c|c|c|}
\hline & \multirow{2}{*}{\multicolumn{2}{|c|}{$\frac{\text { Radiotherapy }}{n=2039}$}} & \multirow{2}{*}{\multicolumn{2}{|c|}{$\begin{array}{l}\text { No radiotherapy } \\
n=351\end{array}$}} & \multirow[t]{3}{*}{$p$ value } \\
\hline & & & & & \\
\hline & $N(\%)$ & $(\%)^{\mathrm{a}}$ & $N(\%)$ & $(\%)^{\mathrm{a}}$ & \\
\hline Age at diagnosis & & & & & $<0.001$ \\
\hline $75-79$ & $1286(63.1)$ & & $69(19.7)$ & & \\
\hline $80-84$ & $627(30.8)$ & & $109(31.1)$ & & \\
\hline$>85$ & $126(6.2)$ & & $173(49.3)$ & & \\
\hline $\mathrm{CCI}$ & & & & & 0.001 \\
\hline 0 & $531(26.0)$ & $(58.3)$ & $52(14.8)$ & $(38.6)$ & \\
\hline 1 & $192(9.4)$ & $(24.0)$ & $39(11.1)$ & $(35.6)$ & \\
\hline$>2$ & $133(6.6)$ & $(17.7)$ & $30(8.6)$ & $(25.8)$ & \\
\hline Unknown & $1183(58.0)$ & & $230(65.5)$ & & \\
\hline Tumor grade & & & & & 0.455 \\
\hline 1 & $570(28.0)$ & $(30.4)$ & $100(28.5)$ & $(32.2)$ & \\
\hline 2 & $929(45.6)$ & $(48.8)$ & $132(37.6)$ & $(42.0)$ & \\
\hline 3 & $407(20.0)$ & $(20.8)$ & $85(24.2)$ & $(25.8)$ & \\
\hline Unknown & $133(6.5)$ & & $34(9.7)$ & & \\
\hline T stage & & & & & $<0.001$ \\
\hline $\mathrm{T} 1$ & $1449(71.1)$ & & $213(60.7)$ & & \\
\hline $\mathrm{T} 2$ & $590(28.9)$ & & $138(39.3)$ & & \\
\hline HR expression & & & & & 0.036 \\
\hline $\mathrm{ER}+$ and/or PR+ & $1682(82.5)$ & $(88.9)$ & $280(79.8)$ & $(84.9)$ & \\
\hline $\mathrm{ER}-$ and PR- & $207(10.2)$ & $(11.1)$ & 48 (13.7) & $(15.1)$ & \\
\hline Unknown & $150(7.4)$ & & $23(6.6)$ & & \\
\hline Her2Neu overexpression & & & & & 0.435 \\
\hline Negative & $1283(62.9)$ & $(91.5)$ & $208(59.3)$ & $(89.6)$ & \\
\hline Positive & $106(5.2)$ & $(8.5)$ & $19(5.4)$ & $(10.4)$ & \\
\hline Unknown & $650(31.9)$ & & $124(35.3)$ & & \\
\hline Surgical margins & & & & & $<0.001$ \\
\hline Free & $1912(93.8)$ & & $302(86.0)$ & & \\
\hline Not free & $91(4.5)$ & & $33(9.4)$ & & \\
\hline Unknown & $36(1.8)$ & & $16(4.6)$ & & \\
\hline Adjuvant endocrine therapy in HR+ & & & & & $\mathbf{0 . 0 2 3}$ \\
\hline Yes & $565(33.6)$ & $(32.6)$ & $157(56.1)$ & $(54.7)$ & \\
\hline No & $1117(66.4)$ & $(67.4)$ & $123(43.9)$ & $(45.3)$ & \\
\hline Chemotherapy & & & & & 0.560 \\
\hline Yes & $3(0.2)$ & & $1(0.3)$ & & \\
\hline No & 2036 (99.9) & & $350(99.7)$ & & \\
\hline Type of hospital & & & & & 0.066 \\
\hline University hospital & $146(7.2)$ & & $35(10.0)$ & & \\
\hline Non-university hospital & $1892(92.8)$ & & $316(90.0)$ & & \\
\hline
\end{tabular}

Bold values represent significant $p$-values

$C C I$ Charlson Comorbidity Index, $H R$ hormone receptor

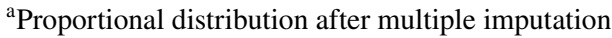

1.49 (95\% CI $0.78-2.83)$ and 1.55 (95\% CI $0.82-2.94)$ for patients treated at hospitals with moderate and lower radiotherapy-use respectively, compared to patients treated at hospitals with higher radiotherapy-use. After adjustment for age, endocrine treatment, and type of hospital, the HRs were 1.46 (95\% CI $0.77-2.78)$ and 1.50 (95\% CI $0.79-2.85)$ respectively. The sensitivity analysis with truncated five-year follow-up demonstrated comparable HRs compared to the primary adjusted analysis: HR 1.50 
Table 2 Characteristics of patients by tertile of hospital radiotherapy-use

\begin{tabular}{|c|c|c|c|c|c|c|c|}
\hline & \multirow{2}{*}{\multicolumn{2}{|c|}{$\begin{array}{l}\text { Higher-use } \\
n=802\end{array}$}} & \multirow{2}{*}{\multicolumn{2}{|c|}{$\begin{array}{l}\text { Moderate-use } \\
n=775\end{array}$}} & \multirow{2}{*}{\multicolumn{2}{|c|}{$\begin{array}{l}\text { Lower-use } \\
n=813\end{array}$}} & \multirow[t]{3}{*}{$p$ value } \\
\hline & & & & & & & \\
\hline & $n(\%)$ & $(\%)^{\mathrm{a}}$ & $n(\%)$ & $(\%)^{\mathrm{a}}$ & $n(\%)$ & $(\%)^{\mathrm{a}}$ & \\
\hline Radiotherapy & $770(96.0)$ & & $682(88.0)$ & & $587(72.2)$ & & $<0.001$ \\
\hline Age at diagnosis & & & & & & & $<0.001$ \\
\hline $75-79$ & $479(59.7)$ & & 449 (57.9) & & $427(52.5)$ & & \\
\hline $80-84$ & $256(31.9)$ & & $239(30.8)$ & & $241(29.6)$ & & \\
\hline$>85$ & $67(8.4)$ & & $87(11.2)$ & & $145(17.8)$ & & \\
\hline $\mathrm{CCI}$ & & & & & & & 0.154 \\
\hline 0 & $230(28.7)$ & $(57.9)$ & $188(24.3)$ & $(56.4)$ & $165(20.3)$ & $(52.0)$ & \\
\hline 1 & $78(9.7)$ & $(23.2)$ & $73(9.4)$ & $(25.4)$ & $80(9.8)$ & $(28.6)$ & \\
\hline$>2$ & $66(8.2)$ & (18.9) & $46(5.9)$ & (18.3) & $51(6.3)$ & $(19.4)$ & \\
\hline Unknown & $428(53.4)$ & & $468(60.4)$ & & $517(63.6)$ & & \\
\hline Tumor grade & & & & & & & 0.083 \\
\hline 1 & $243(30.3)$ & $(32.5)$ & 224 (28.9) & (31.9) & $203(25.0)$ & $(27.7)$ & \\
\hline 2 & $353(44.0)$ & $(47.1)$ & $327(42.2)$ & $(45.9)$ & $381(46.9)$ & $(50.4)$ & \\
\hline 3 & $155(19.33)$ & $(20.4)$ & $166(21.4)$ & $(22.3)$ & $171(21.0)$ & $(21.9)$ & \\
\hline Unknown & $51(6.4)$ & & $58(7.5)$ & & $58(7.1)$ & & \\
\hline T stage & & & & & & & 0.822 \\
\hline $\mathrm{T} 1$ & $564(70.3)$ & & $534(68.9)$ & & $564(69.4)$ & & \\
\hline $\mathrm{T} 2$ & $238(29.7)$ & & $241(31.1)$ & & $249(30.6)$ & & \\
\hline HR expression & & & & & & & 0.699 \\
\hline $\mathrm{ER}+$ and/or PR+ & $674(84.0)$ & $(89.8)$ & $612(79.0)$ & $(86.0)$ & $676(83.2)$ & $(89.2)$ & \\
\hline $\mathrm{ER}-$ and PR- & $77(9.6)$ & $(10.2)$ & $97(12.5)$ & $(14.0)$ & $81(10.0)$ & $(10.9)$ & \\
\hline Unknown & $51(6.4)$ & & $66(8.5)$ & & $56(6.9)$ & & \\
\hline Her2Neu overexpression & & & & & & & 0.692 \\
\hline Negative & $519(64.7)$ & $(92.2)$ & $478(61.7)$ & $(90.0)$ & $494(60.8)$ & $(91.5)$ & \\
\hline Positive & $39(4.9)$ & (7.9) & $47(6.1)$ & $(10.0)$ & $39(4.8)$ & $(8.5)$ & \\
\hline Unknown & $244(30.4)$ & & $250(32.3)$ & & $280(34.44)$ & & \\
\hline Surgical margins & & & & & & & 0.465 \\
\hline Free & $747(93.1)$ & & $723(93.3)$ & & $744(91.5)$ & & \\
\hline Not free & $42(5.2)$ & & $35(4.5)$ & & $47(5.8)$ & & \\
\hline Unknown & $13(1.6)$ & & $17(2.2)$ & & $22(2.7)$ & & \\
\hline Adjuvant endocrine therapy in HR+ & & & & & & & 0.023 \\
\hline Yes & $238(35.3)$ & $(34.3)$ & $202(33.0)$ & $(32.5)$ & $282(41.7)$ & $(40.0)$ & \\
\hline No & $436(64.7)$ & $(65.7)$ & $410(67.0)$ & $(67.5)$ & $394(58.3)$ & $(60.0)$ & \\
\hline Chemotherapy & & & & & & & 0.186 \\
\hline Yes & $1(0.1)$ & & $0(0)$ & & $3(0.4)$ & & \\
\hline No & 801 (99.9) & & $775(100)$ & & $810(99.6)$ & & \\
\hline Type of hospital & & & & & & & $<0.001$ \\
\hline University hospital & $37(4.6)$ & & $29(3.7)$ & & $115(14.2)$ & & \\
\hline Non-university hospital & $764(95.4)$ & & $746(96.3)$ & & $698(85.9)$ & & \\
\hline
\end{tabular}

Bold values represent significant $p$-values

$C C I$ Charlson Comorbidity Index, $H R$ hormone receptor

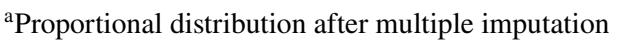


Fig. 1 Cumulative incidence of locoregional recurrence in highuse, moderate-use, and low-use radiotherapy hospitals
Table 3 Cox proportional hazards analysis for time to locoregional recurrence by hospital radiotherapy-use

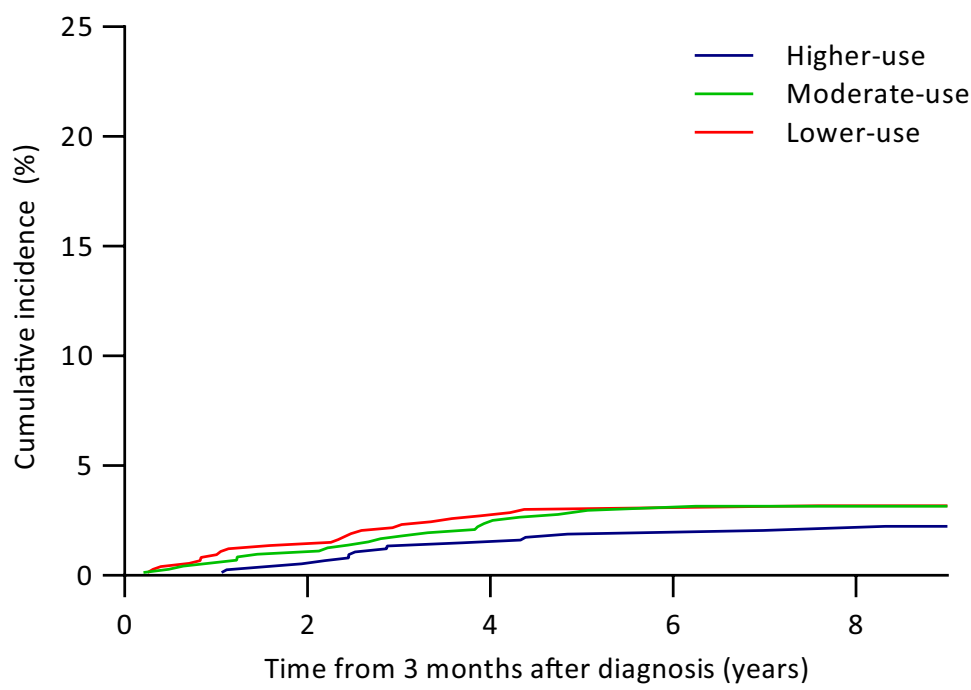

Number at risk (events) Moderate-use 743

$\begin{array}{cccc}(4) & 691 & (7) & 619 \\ (7) & 644 & (10) & 571 \\ (10) & 659 & (10) & 559\end{array}$

(3)

(2) 125

(1) 129

(1) 112

(1)

733

(10) 659
(1) 94
(4) 137

\begin{tabular}{|c|c|c|c|c|}
\hline & \multicolumn{4}{|c|}{ Cumulative incidences $(95 \% \mathrm{CI})$} \\
\hline & Five-year follow-up ${ }^{\mathrm{a}}$ & Nine-year follow-up ${ }^{a}$ & Univariable $\mathrm{HR}^{\mathrm{b}}(95 \% \mathrm{CI})$ & $\begin{array}{l}\text { Multivariable } \\
\mathrm{HR}^{\mathrm{b}, \mathrm{c}}(95 \% \mathrm{CI})\end{array}$ \\
\hline Higher-use & $1.9(1.1-3.1)$ & $2.2(1.3-3.6)$ & Reference & Reference \\
\hline Moderate-use & $2.8(1.8-4.2)$ & $3.1(2.0-4.6))$ & $1.49(0.78-2.83)$ & $1.46(0.77-2.78)$ \\
\hline Lower-use & $3.0(1.9-4.4)$ & $3.2(2.1-4.7)$ & $1.55(0.82-2.94)$ & $1.50(0.79-2.85)$ \\
\hline
\end{tabular}

$H R$ hazard ratio, $C I$ confidence interval

${ }^{\text {a } F o l l o w-u p ~ f r o m ~ l a n d m a r k ~ a t ~} 3$ months after diagnosis

${ }^{\mathrm{b}}$ Calculated with complete follow-up time

${ }^{\mathrm{c}}$ Adjusted for age (continuous), endocrine therapy and type of hospital

(95\% CI 0.76-2.96) and 1.59 (95\% CI 0.81-3.14) (Supplementary Table).

\section{Discussion}

The present study shows that locoregional recurrence rates are low in patients aged $\geq 75$ years who underwent BCS, even in patients treated in hospitals with lower radiotherapy-use. No association was found between radiotherapyuse and locoregional recurrence risk.

Our study adds to available evidence, since the low locoregional recurrence risks that were seen in previous RCTs were confirmed in this population-based cohort in which only $39.3 \%$ of the patients was treated with endocrine therapy. Therefore, concerns of an increased locoregional recurrence risk among older patients not treated with endocrine therapy are contradicted. We argue that this can be explained by the declining residual life expectancy and increasing risk of dying from other causes than breast cancer, so-called competing mortality, among the older population of patients with breast cancer [17].

The low locoregional recurrence rates reported in this study support the allowance of omission of radiotherapy in patients aged $\geq 75$ years, even when patients are not treated with endocrine treatment. This is strengthened by the fact that we found locoregional recurrence risks in patients treated in hospitals with higher radiotherapy-use (average $96 \%$ ) in our study (1.9\% after 5 and $2.2 \%$ after 9 years), that were similar to patients in the radiotherapy-arm of the CALGB 9343 trial (1\% after 5 and 2\% after 10 years). This hallmark trial randomized patients aged $\geq 70$ years with T1N0 breast cancer using endocrine treatment between radiotherapy or no radiotherapy after BCS. The trial exclusively included patients receiving endocrine treatment, whereas only $39.3 \%$ of the patients in our study was not 
treated with endocrine treatment conform Dutch treatment guidelines. Moreover, adherence to endocrine treatment was likely more typical for the true older population as population-based data were used.

Although RCTs provide the highest level of evidence for treatment efficacy, their external validity is often questioned. Therefore, results from observational studies can add to the generalizability. However, all observational studies are susceptible for confounding by indication because treatment allocation is likely based on reasons associated with outcomes. The validity of the results strongly depends on the ability to reduce such confounding.

Especially in older populations, directly comparing patients who are treated differently leads to biased effect estimates as treatment decisions are made on the combination and interaction of disease and patient related factors for which it appears impossible to adjust [13]. Furthermore, information on important confounding factors may be missing in observational studies, while conventional methods to reduce confounding such as multivariable analysis or propensity score matching rely on measured variables. Consequently, aspects of general health such as comorbidity, physical and cognitive functioning are often not taken into account. As a result, using conventional methods generally results in an overestimation of effect estimates, and may even demonstrate an opposite causal effect $[13,18,19]$.

Many previous observational studies addressed the omission of radiotherapy after BCS in older patients. Some advocate that radiotherapy may be omitted [20-23], whereas others state that it is unsafe due to a higher risk of locoregional recurrence [24-26] or even worse breast cancer specific and overall survival [25, 27-29]. Although different patient selections could play a role in the varying findings, results of these studies using conventional methods to adjust for confounding may have been biased to some extent. For example, the worse overall survival in patients treated without radiotherapy (not found in RCTs) could be in fact a reflection of the lower probability to receive radiotherapy in patients with higher competing mortality risk [25, 28]. Furthermore, even when disease-specific outcomes are used, confounding by indication can still cause bias through differential censoring of patients dying from other causes [30].

Instead of a conventional statistical approach, we used an instrumental variable-like approach by using hospital variation in radiotherapy-use to minimize confounding by indication [13]. We demonstrated that patients treated with and without radiotherapy differed in many aspects, but using hospital variation, the constructed radiotherapy groups were fairly similar. Comorbidity is an important confounding factor as it strongly influences whether a patient receives treatment, and at the same time, affects survival and disease-specific outcomes such as locoregional recurrence risk indirectly. Therefore, the fact that the groups were similar concerning comorbidity indicates that confounding by comorbidity was effectively resolved. Notably, we expected patients not treated with radiotherapy to have more favorable tumor characteristics, but on the contrary, we observed larger tumors and less hormone receptor-positivity. This may imply that the decision for radiotherapy depends more on patient related factors than on tumor characteristics.

Our study has important limitations. Foremost, although using hospital variation may result in more valid results, we could only assess the effect of a difference of $23.8 \%$ in radiotherapy-use. Consequently, the results apply to patients in whom the decision for radiotherapy was influenced by hospital variation, but this selection is not readily identifiable. However, we do not advocate that radiotherapy should be omitted in all patients, but rather advise against routinely treating all older patients with radiotherapy. Second, the low event rate prevented us from exploring subgroups with a differential radiotherapy-use effect. Third, residual confounding could not be completely ruled out because some imbalances between the radiotherapy-use groups persisted. For this reason, we also performed a multivariable analysis. Last, the absolute risk of locoregional recurrence for patients treated without radiotherapy could not be provided as a proportion of the patients treated in the lower-use hospitals still received radiotherapy.

To obtain the absolute locoregional recurrence risk for patients in whom radiotherapy after BCS is omitted, the ongoing TOP-1 (Tailored treatment in Older Patients) study (BOOG study number 2016-01) was recently initiated and is currently running in almost all breast cancer clinics in the Netherlands. This prospective cohort study includes patients aged $\geq 70$ years with endocrine receptorpositive grade 1 tumors up to $2 \mathrm{~cm}$ and grade 2 tumors up to $1 \mathrm{~cm}$ who are treated without radiotherapy after BCS, and assesses whether the LRR remains below the prespecified limit of 3.9\%. Notably, none of these patients is treated with endocrine therapy following Dutch treatment guidelines. To be able to assess the generalizability of the results, all patients are characterized by a geriatric assessment. Secondary outcomes are quality of life and toxicity.

In conclusion, despite endocrine treatment being prescribed in only $39.3 \%$ of the patients, locoregional recurrence risk after BCS in patients aged $\geq 75$ years with T1-2N0 breast cancer was low, even in patients treated at hospitals with lower radiotherapy-use. Our study provides reasonable grounds to consider omission of radiotherapy after BCS. At older age, the frequent hospital visits required for radiotherapy can prove a substantial burden due to impaired mobility, lack of transportation, lack of social support, and caregiver responsibilities. Therefore, 
instead of routinely admitting radiotherapy after BCS, a shared-decision making approach is appropriate in all patients aged $\geq 75$ years with T1-2N0 breast cancer.

Acknowledgements The authors would like to thank the Netherlands Comprehensive Cancer Organisation (IKNL) for the data collection.

Funding This work was supported by ZonMw (The Netherlands Organisation for Health Research and Development) (Grant Number $843002623)$

\section{Compliance with ethical standards}

Conflict of interest The authors declare that they have no conflicts of interest.

Ethical approval All procedures performed in studies involving human participants were in accordance with the ethical standards of the institutional and/or national research committee and with the 1964 Helsinki declaration and its later amendments or comparable ethical standards.

Informed consent Data from the Netherlands Cancer Registry are fully anonymized prior to being made available to researchers, so data cannot be traced back to the individual patient. Therefore, no informed consent was required from the included patients and there was no need for approval of the medical ethical committee.

Open Access This article is distributed under the terms of the Creative Commons Attribution 4.0 International License (http://creativeco mmons.org/licenses/by/4.0/), which permits unrestricted use, distribution, and reproduction in any medium, provided you give appropriate credit to the original author(s) and the source, provide a link to the Creative Commons license, and indicate if changes were made.

\section{References}

1. Kunkler IH, Williams LJ, Jack WJL, Cameron DA, Dixon JM (2015) Breast-conserving surgery with or without irradiation in women aged 65 years or older with early breast cancer (PRIME II): a randomised controlled trial. Lancet Oncol 16(3):266-273

2. Hughes KS, Schnaper LA, Bellon JR, Cirrincione CT, Berry DA, McCormick B, Muss HB, Smith BL, Hudis CA, Winer EP et al (2013) Lumpectomy plus tamoxifen with or without irradiation in women age 70 years or older with early breast cancer: long-term follow-up of CALGB 9343. J Clin Oncol 31(19):2382-2387

3. EBCTCG (2011) EBCTCG: effect of radiotherapy after breastconserving surgery on 10-year recurrence and 15-year breast cancer death: meta-analysis of individual patient data for 10801 women in 17 randomised trials. Lancet 378(9804):1707-1716

4. Gradishar WJ, Anderson B, Balassanian R, Blair SL, Burstein H, Cyr A, Elias AD, Farrar WB, Forero A, Giordano SH et al (2017) NCCN guidelines insights: breast cancer, Version 1.2017. 15

5. McCormick B, Ottesen RA, Hughes ME, Javid SH, Khan SA, Mortimer J, Niland JC, Weeks JC, Edge SB (2014) Impact of guideline changes on use or omission of radiation in the elderly with early breast cancer: practice patterns at National Comprehensive Cancer Network institutions. J Am Coll Surg 219(4):796-802

6. Biganzoli L, Wildiers H, Oakman C, Marotti L, Loibl S, Kunkler I, Reed M, Ciatto S, Voogd AC, Brain E et al (2012) Management of elderly patients with breast cancer: updated recommendations of the International Society of Geriatric Oncology (SIOG) and
European Society of Breast Cancer Specialists (EUSOMA). Lancet Oncol 13(4):e148-e160

7. Allemani C, Sant M, Weir HK, Richardson LC, Baili P, Storm H, Siesling S, Torrella-Ramos A, Voogd AC, Aareleid T et al (2013) Breast cancer survival in the US and Europe: a CONCORD highresolution study. Int J Cancer 132(5):1170-1181

8. van Herk-Sukel MP, van de Poll-Franse LV, Voogd AC, Nieuwenhuijzen GA, Coebergh JW, Herings RM (2010) Half of breast cancer patients discontinue tamoxifen and any endocrine treatment before the end of the recommended treatment period of 5 years: a population-based analysis. Breast Cancer Res Treat 122(3):843-851

9. NABON. Richtlijn Mammacarcinoom 2012, versie 2

10. van de Water W, Kiderlen M, Bastiaannet E, Siesling S, Westendorp RG, van de Velde CJ, Nortier JW, Seynaeve C, de Craen AJ, Liefers GJ (2014) External validity of a trial comprised of elderly patients with hormone receptor-positive breast cancer. J Natl Cancer Inst 106(4):dju051

11. Frederick L, Greene CMB, Haller DG, Morrow M (2002) AJCC cancer staging manual, 6th edn. Springer, New York

12. Moossdorff M, van Roozendaal LM, Strobbe LJ, Aebi S, Cameron DA, Dixon JM, Giuliano AE, Haffty BG, Hickey BE, Hudis CA et al (2014) Maastricht Delphi consensus on event definitions for classification of recurrence in breast cancer research. J National Cancer Inst 106(12)

13. Bosco JL, Silliman RA, Thwin SS, Geiger AM, Buist DS, Prout MN, Yood MU, Haque R, Wei F, Lash TL (2010) A most stubborn bias: no adjustment method fully resolves confounding by indication in observational studies. J Clin Epidemiol 63(1):64-74

14. Sterne JA, White IR, Carlin JB, Spratt M, Royston P, Kenward MG, Wood AM, Carpenter JR (2009) Multiple imputation for missing data in epidemiological and clinical research: potential and pitfalls. BMJ 338:b2393

15. Marshall A, Altman DG, Holder RL, Royston P (2009) Combining estimates of interest in prognostic modelling studies after multiple imputation: current practice and guidelines. BMC Med Res Methodol 9:57

16. Putter H, Fiocco M, Geskus RB (2007) Tutorial in biostatistics: competing risks and multi-state models. Stat Med 26(11):2389-2430

17. Derks MGM, Bastiaannet E, van de Water W, de Glas NA, Seynaeve C, Putter H, Nortier JWR, Rea D, Hasenburg A, Markopoulos $\mathrm{C}$ et al (2018) Impact of age on breast cancer mortality and competing causes of death at 10 years follow-up in the adjuvant TEAM trial. Eur J Cancer 99:1-8

18. de Glas NA, Hamaker ME, Kiderlen M, de Craen AJ, Mooijaart SP, van de Velde CJ, van Munster BC, Portielje JE, Liefers GJ, Bastiaannet E (2014) Choosing relevant endpoints for older breast cancer patients in clinical trials: an overview of all current clinical trials on breast cancer treatment. Breast Cancer Res Treat 146(3):591-597

19. Giordano SH, Kuo YF, Duan Z, Hortobagyi GN, Freeman J, Goodwin JS (2008) Limits of observational data in determining outcomes from cancer therapy. Cancer 112(11):2456-2466

20. Wickberg A, Liljegren G, Killander F, Lindman H, Bjohle J, Carlberg M, Blomqvist C, Ahlgren J, Villman K (2018) Omitting radiotherapy in women $>/=65$ years with low-risk early breast cancer after breast-conserving surgery and adjuvant endocrine therapy is safe. Eur J Surg Oncol 44(7):951-956

21. Kim YJ, Shin KH, Kim K (2019) Omitting adjuvant radiotherapy for hormone receptorpositive early-stage breast cancer in old age: a propensity score matched SEER analysis. Cancer Res Treat 51(1):326-336

22. Nichol AM, Chan EK, Lucas S, Smith SL, Gondara L, Speers C, Tyldesley S (2017) The use of hormone therapy alone versus 
hormone therapy and radiation therapy for breast cancer in elderly women: a population-based study. Int J Radiat Oncol Biol Phys 98(4):829-839

23. Valassiadou K, Morgan DA, Robertson JF, Pinder SE, Cheung KL (2007) Successful management of elderly breast cancer patients treated without radiotherapy. World J Surg Oncol 5:62

24. Potter R, Gnant M, Kwasny W, Tausch C, Handl-Zeller L, Pakisch B, Taucher S, Hammer J, Luschin-Ebengreuth G, Schmid M et al (2007) Lumpectomy plus tamoxifen or anastrozole with or without whole breast irradiation in women with favorable early breast cancer. Int J Radiat Oncol Biol Phys 68(2):334-340

25. Truong PT, Bernstein V, Lesperance M, Speers $\mathrm{CH}$, Olivotto IA (2006) Radiotherapy omission after breast-conserving surgery is associated with reduced breast cancer-specific survival in elderly women with breast cancer. Am J Surg 191(6):749-755

26. Smith BD, Gross CP, Smith GL, Galusha DH, Bekelman JE, Haffty BG (2006) Effectiveness of radiation therapy for older women with early breast cancer. J Natl Cancer Inst 98(10):681-690

27. Ali AA, Tawk R, Xiao H, Campbell E, Semykina A, Montero AJ, Mogos M, Diaby V (2018) Comparative effectiveness of radiotherapy for early-stage hormone receptor-positive breast cancer in elderly women using real-world data. Cancer Med $8(1): 117-127$

28. Daugherty EC, Daugherty MR, Bogart JA, Shapiro A (2016) Adjuvant radiation improves survival in older women following breast-conserving surgery for estrogen receptor-negative breast cancer. Clin Breast Cancer 16(6):500-506; e502

29. Keating NL, Landrum MB, Brooks JM, Chrischilles EA, Winer EP, Wright K, Volya R (2011) Outcomes following local therapy for early-stage breast cancer in non-trial populations. Breast Cancer Res Treat 125(3):803-813

30. de Glas NA, Kiderlen M, Vandenbroucke JP, de Craen AJ, Portielje JE, van de Velde CJ, Liefers GJ, Bastiaannet E, Le Cessie $S$ (2016) Performing survival analyses in the presence of competing risks: a clinical example in older breast cancer patients. J Natl Cancer Inst 108(5):djv366

Publisher's Note Springer Nature remains neutral with regard to jurisdictional claims in published maps and institutional affiliations. 